\title{
«LAUDATIO» AL PROFESOR EUGENIO COSERIU CON MOTIVO DE SU NOMBRAMIENTO COMO «DOCTOR HONORIS CAUSA», IN MEMORIAM, DE LA UNIVERSIDAD DE LAS PALMAS DE GRAN CANARIA, EL DÍA 27 DE JUNIO DE 2003
}

\author{
MAXIMIANO TRAPERO \\ Catedrático de Filología Española. Universidad de Las Palmas de Gran Canaria
}

\begin{abstract}
Excelentísimo Señor Rector Magnífico de la Universidad de LPGC, Excelentísimos e Ilustrísimos Señores, Claustro de Profesores, Colegas y Alumnos, Señoras y Señores:
\end{abstract}

Cuán lejos estábamos de imaginar que cuando, desde las Facultades de Filología, de Traducción e Interpretación y de Formación del Profesorado, iniciamos la propuesta de nombramiento del Prof. Eugenio Coseriu como «Doctor honoris causa» de nuestra Universidad de Las Palmas de Gran Canaria, llegado el momento de concedérselo, íbamos a encontrarnos con una silla vacía. Los trámites burocráticos han caminado, en este caso, a ritmo de hombres, cuando el destino anduvo a ritmo de muerte («Temprano levantó la muerte el vuelo...»). Él, Eugenio Coseriu, a quien tanta ilusión y alegría le había dado la noticia de esta propuesta; a él, que tanto deseo tenía de volver a Canarias. Y nosotros, que por demás de perder para siempre una guía de pensamiento y de ciencia seguros, nos vemos privados hoy de su presencia y de su palabra, tan sabia, tan elocuente, tan incitante siempre.

Pero no gastemos tiempo ya en lamentar lo irreparable («que querer hombre vivir, / cuando Dios quiere que muera, / es locura») y vayamos a lo que hoy toca, que es ensalzar la figura y la obra de quien ha sido considerado como «el lingüista más importante de la segunda mitad del siglo XX», para algunos incluso «uno de los lingüistas más grandes de todos los tiempos», para otros, aún más, «uno de los grandes humanistas de todos los tiempos», y hay para quien la obra de Coseriu «alcanzará su verdadera trascendencia en el siglo XXI». Para mí, el mayor «arquitecto» que ha tenido la lingüística moderna, lo que quiere decir de la historia, por cuanto la lingüística, como estudio científico del lenguaje, propiamente nació con Saussure, a principios del siglo XX, porque cualquier problema lingüístico particular que se considere, cualquiera, halla en la teoría coseriana el lugar exacto en que ubicarse, y desde él puede ser entendido - y explicado - cabalmente.

Odisea, $\mathrm{n}^{\circ} 3,2003$, ISSN 1578-3820, pags. 11-21 
Porque la obra de Eugenio Coseriu no se ha limitado al estudio de una parcela concreta de la lingüística, sino que abarca todas los aspectos que puedan considerarse en una lingüística integral. Puede decirse que en Coseriu se ha adaptado bien el clásico lema de Menandro y de Terencio: «Homo sum et nihil humani a me alienum puto», es decir, «Lingüista soy y nada de lo que haya en la lingüística me puede ser ajeno». Y así, su obra interesa y es fundamental a la filosofía del lenguaje, a la teoría del lenguaje y de la lingüística; a la fonología, a la teoría gramatical y a la semántica léxica; a la lingüística del hablar y a la lingüística del texto; a la dialectología, a la sociolingüística y a la estilística de la lengua; a la gramática histórica y a la historia de las lenguas; a la lingüística «aplicada» y a la historia de la lingüística. Gracias a su magistral rastreo de las obras que verdaderamente han contribuido al desarrollo de la lingüística podemos ver hoy iluminada una disciplina que hasta él no tenía sino sucesivas estancias en penumbra.

Por eso la propuesta de su nombramiento como Doctor «honoris causa» de Universidad de Las Palmas de Gran Canaria, aparte su vinculación directa con nuestra Universidad, a la que posteriormente me referiré, partió conjuntamente de los tres Centros antedichos, por cuanto la actividad investigadora del Profesor Coseriu fue concurrente con los planes de estudio de cada uno de ellos y particularmente importante en las áreas de la lingüística general, de la filología románica y de la filología española, de la traducción y de la didáctica de la lengua materna.

\section{UNA OBRA UNIVERSAL}

Eugenio Coseriu fue un verdadero sabio. Su formación y los saberes acumulados lo hicieron universal. Rumano de nacimiento, italiano de formación, alemán de residencia en su etapa de madurez, romanista de por vida, pero español —o por mejor decir, «hispano»— de corazón: fue en un país de la Hispanidad, en Uruguay, donde aparecieron sus primeras obras fundamentales y allí donde formuló el esquema central de toda su teoría.

La obra de Coseriu ha tenido también un reconocimiento universal, y de hecho sus libros y su producción científica están traducidos a las principales lenguas de cultura del mundo. De ese reconocimiento universal hablan también los más de 30 Doctorados honoris causa con que ha sido distinguido por Universidades de todo el mundo, entre las que queremos destacar las iberoamericanas de Montevideo (1980), San Juan (1981), Córdoba (1987), Mendoza (1993), Santiago de Chile (1988), Lima (1994), Arequipa (1994) y Río de Janeiro (1995); y las españolas: Complutense de Madrid (1989), Granada (1993), Vigo (1995), Salamanca (1995), Autónoma de Madrid (1999) y ahora la de Las Palmas (2003), ya «in memoriam».

En verdad que aquella «sed de universalidad» a la que Coseriu aspiró desde joven y que reiteradamente hizo explícita, la logró, tanto por el alcance de su pensamiento como por el reconocimiento que éste ha tenido.

Coseriu nos ha ofrecido una teoría - una verdadera doctrina - que no se acaba en sí misma, sino que, bien al contrario, es capaz de poner en marcha todos los mecanismos prácticos para explicar y comprender el funcionamiento de esos complejísimos sistemas que llamamos lenguas. Y lo ha hecho, pausadamente, a lo largo de toda una vida. Su teoría no está en un solo estudio, en un solo libro, sino en el conjunto de su obra, toda ella perfecta- 
mente estructurada, pura arquitectura, como resultado de una mente clarividente, de una inteligencia superior.

\section{OÍR SUS PALABRAS Y CONOCER SU PENSAMIENTO}

En un acto de investidura de Doctor honoris causa, es tradición bien asentada que un miembro del claustro de la Universidad que lo concede lea la «laudatio» en que se expongan las razones por las que el «Doctorando» merece tan alta distinción. Pero forma parte también de esa misma tradición que el nuevo Doctor, una vez investido de los simbólicos atributos que el Rector le otorga, pronuncie un «discurso», una lección relacionada con su mundo académico e investigativo.

La ausencia de Eugenio Coseriu nos priva hoy de oír su propia voz, sus propias razones. No sabemos qué discurso tendría pensado, si no ya escrito o al menos esbozado, para este acto, pero podemos intuirlo, a juzgar por los que pronunció en las otras Universidades españolas al recibir su correspondiente Doctorado honoris causa. Vale la pena leerlos y releerlos, pues en ellos encontramos la autorreflexión de un hombre dedicado por entero a la ciencia y que quiso acomodar su actuación a una conducta ética. El pensamiento que subyace en esos discursos viene a ser para mí el prontuario más claro y contundente del profesor universitario, un modelo de conducta, el inestimable «abstrat» de una vida entera dedicada al estudio y a la enseñanza, hecho además por quien mejor se conocía, por él mismo, para explicitar las claves sobre las que se asienta el edificio de una vida y de una obra ejemplares que han confluido en una misma realidad. Vale la pena conocer su pensamiento y hacerlo propio. Por eso, a mi «laudatio», cuando al caso venga, sumaré las palabras directas que Eugenio Coseriu podría haber pronunciado aquí, extraídas de las que en circunstancias paralelas pronunció.

El Profesor Coseriu dijo en ocasiones como ésta:

Para mí una distinción de tanta entidad es ante todo una ocasión de reflexión sobre mí mismo y sobre el sentido de mi actividad científica y, con ello, sobre las razones que pueden haber tenido en consideración los promotores del título honorífico que se ha querido conferirme.

A ello trataremos de responder en lo que sigue.

\section{$\mathrm{CINCO} « \mathrm{PRINCIPIOS»} \mathrm{ÉTICOS}$}

Cinco han sido los «principios» éticos en los que ha basado Coseriu su actividad intelectual, a saber:

1. Principio del realismo o de la absoluta objetividad, que consiste — en formulación platónica- en decir las cosas como son y que se convierte en la «norma intrínseca de toda ciencia digna de este nombre». Decir las cosas como son parece fácil, pero en realidad es sumamente difícil, ya que «los hechos sólo adquieren su pleno sentido en el conjunto de sus conexiones», lo cual implica, en su dimensión ética, «la renuncia a todo necio afán de originalidad». Fácil es decir las cosas como no son, o como son parcialmente, o sólo desde 
una perspectiva particular. «La ciencia auténtica - concluye Coseriu - no se propone deslumbrar a los legos».

2. Principio del humanismo o del «saber originario», que consiste en entender el lenguaje - como cualquier otra actividad humana-, como expresión libre y creadora del hombre, es decir, entender que el centro de la filología está en el hombre; principio formulado por Aristóteles, que define el lenguaje como logos semantikós. Y de este principio se derivan otros cinco, que definen las características esenciales del lenguaje: la creatividad, la semanticidad, la alteridad, la historicidad y la materialidad, siendo primarios y universales los tres primeros, y secundarios y derivados los otros dos.

3. Principio de la tradición, que consiste en comprender que la lingüística, como ciencia cultural que es, se asienta en una tradición en que se han planteado reiteradamente los mismos problemas, sólo que, en cada tiempo, vistos de manera diferente, con metodología distinta. Eso es lo que se expresa bajo la fórmula de tradición y novedad. «Quien, en el ámbito de la ciencia cultural — dice Coseriu en un lugar-, ignora o rechaza deliberadamente toda la tradición y dice (o pretende decir) sólo cosas nuevas, no dice nada culturalmente válido, ya que no responde a una exigencia de la comunidad correspondiente y no se inserta en la cultura a la que pretende contribuir». Y continúa en otro: «La lingüística no puede ser sólo repetición mecánica de la tradición, porque, en tal caso, dejaría de ser ciencia viva, ni sólo absoluta novedad, ya que con ello no correspondería a intuiciones comunes y reconocibles; debe ser, precisamente, tradición y novedad, asegurando la continuidad de los esfuerzos de tantas generaciones de estudiosos»».

4. Principio del antidogmatismo, que recomienda no rechazar ninguna teoría en su totalidad, sino buscar el núcleo de verdad que cada una ha de contener, las intuiciones certeras en que probablemente se basa, el principio de coherencia que toda teoría debe tener. «Se trata de considerar — dice Coseriu-, desde una concepción unitaria y fundada, y sobre todo, desde la compleja realidad del lenguaje, todas las teorías y concepciones y establecer los alcances y límites de cada una de ellas: lo que cada una puede y no debe dar».

5. Principio del bien público o de la responsabilidad social, que exige una actitud ética por parte del lingüista y cuya formulación sería: el lenguaje funciona por y para los hablantes, no por y para los lingüistas. «Por y para los hablantes —explicita Coseriu-. La lingüística científica y teórica suele concentrarse en el por y descuidar, o considerar sólo marginalmente, el para, que se atribuye a lo sumo a la lingüística aplicada». Por ello, todo lo que interesa al hablante debe interesar al lingüista, también al lingüista teórico.

\section{SUS MAESTROS}

Coseriu fue un lingüista filósofo o un filósofo de la lengua. La sólida formación que adquirió en estas dos disciplinas, en la filosofía y en la lingüística, hizo posible que en su obra aparezcan siempre fusionadas, iluminándose mutuamente, y en ello se basa no poco de su verdadera originalidad y magisterio.

Sus maestros reconocidos en el campo de la filosofía fueron Platón, Aristóteles, Leibniz, Vico, Kant, Hegel, Husserl, Croce y Ortega (especialmente éste en lo concerniente a la filosofía del lenguaje). Sus maestros, también reconocidos, en el campo de la lingüística fueron Humboldt, Saussure, Pagliaro (éste en la consideración de la lengua como técnica 
histórica del hablar) y Menéndez Pidal (éste sobre todo en la intuición esencial de varias lenguas funcionales dentro de una lengua histórica).

El magisterio, en el caso de Eugenio Coseriu, debe entenderse en un proceso dialéctico: el paso del saber intuitivo al saber reflexivo y fundado; el necesario camino de ida y vuelta que debe recorrer siempre el conocimiento, desde la teoría a la práctica, para volver desde ésta de nuevo a la teoría; un proceso de constante ir y venir para que la teoría no sea otra cosa que sustento y explicación de los hechos reales y efectivos y no de supuestos posibles o imaginados. Ese proceso dialéctico lo ejemplificó muy bien Coseriu, metafóricamente:

El lingüista [...] —dijo— debe ser al mismo tiempo botánico y jardinero; debe llegar a la constitución de tipos abstractos e ideales de flores, pero sólo para cuidar mejor la vida caprichosa y cada vez sorprendente y nueva de las flores vivas y concretas de su jardín, debe ser botánico, para ser mejor jardinero.

Y claro está que ese itinerario de ida y vuelta, Coseriu lo pudo hacer desde el conocimiento portentoso que él tenía de las lenguas concretas, un caso de multililingüismo único entre los hombres de ciencia; su lengua materna, el rumano, le llevó al conocimiento de las otras lenguas románicas: el italiano, el español, el francés, el portugués y el catalán; y desde ellas buceó y aprendió el latín y el griego clásicos; por otra parte, la proximidad de su tierra natal con el mundo eslavo le llevó al conocimiento del ruso, del búlgaro, del serbio y del croata; su mundo cultural y profesional le llevó, a su vez, al dominio del alemán y del inglés, y hasta empezó a entender (y hacer entenderse) en japonés. Ni él mismo sabía decir con exactitud las lenguas que hablaba, pero sí que ese conocimiento que de ellas tenía le había proporcionado la base para la reflexión teórica sobre los hechos lingüísticos generales.

\section{LA VIDA DE UN HOMBRE VIVIDA PARA LA CIENCIA}

Eugenio Coseriu nació el 28 de julio de 1921 en Mihaileni, Rumania, un pequeño pueblo de lo que hoy es la República de Moldavia, y allí hizo sus estudios primarios y secundarios. Fue al comienzo de la Segunda Guerra Mundial, cuando los rusos invadieron Rumania, que el joven Coseriu decidió exiliarse en Italia y continuar allí sus estudios universitarios. Pasaron muchos años hasta que pudo volver a su país, después de la dictadura comunista. Y fue entonces cuando Rumania lo acogió como a uno de sus hijos predilectos y lo llenó de reconocimientos y de honores. Por su parte, el reconocimiento de Coseriu a su propio país lo expresó así:

La excelente escuela rumana de mi tiempo, empezando por la escuela primaria, me ha proporcionado el marco ideal y la base de mi desarrollo intelectual. Y — sin que yo lo advirtiera con claridad en aquel entonces: lo he advertido mucho más tarde- ha determinado los rumbos de mi actividad ulterior, despertando en mí el interés y la pasión por el saber fundado [...] y la 'sed de universalidad'.

En Italia estudió primero en la Universidad de Roma (1940-44) y luego en las de Padua (1944-45) y de Milán (1945-49). Y en Italia fue donde hizo los dos Doctorados que marcarían 
su dedicación a la investigación: el de Letras en la Universidad de Roma (1944) y el de Filosofía en la de Milán (1949). Su reconocimiento a Italia lo expresó de la siguiente manera:

Italia me ha dado los fundamentos propiamente dichos de la ciencia, ha encauzado mi 'sed de universalidad' hacia dominios concretos, ha ensanchado y, al mismo tiempo, ha definido mis horizontes, me ha enseńado el método crítico. Por ello, por mucho tiempo, me he considerado — y, en parte, me sigo considerando — representante de la lingüística italiana.

Recién doctorado, se le presentó la oportunidad de ocupar una plaza de Profesor en la Universidad de Montevideo, y allí enseñó por un periodo de trece años (1950-1963), siendo aquella, posiblemente, la etapa más fecunda de su vida, en la que intuyó y diseñó las grandes líneas de su pensamiento lingüístico. Allí fue donde formuló explícitamente los fundamentos de su lingüística integral, los conceptos de sistema, norma y habla y los de diacronía, sincronía y pancronía, con que superaría las célebres antinomias saussureanas; los de forma y sustancia del lenguaje; su formulación de la lexemática (y de toda la semántica estructural); la teoría de los campos léxicos; la distinción fundamental entre lengua histórica y lengua funcional; los conceptos de discurso repetido y técnica de discurso, etc. Así recordaba agradecido Coseriu a Uruguay:

Uruguay, ese gran pequeño país que me ha otorgado su confianza cuando yo, en el campo de la ciencia, era todavía un desconocido y no constituía más que una posible promesa y que me ha dado una identidad cívica cuando yo no tenía ninguna, por lo cual, treinta ańos después de mi vuelta a Europa [esto lo escribía en 1993] sigo conservando la nacionalidad uruguaya. Esto en lo práctico. Pero en lo espiritual y lo universal humano, la República del Uruguay ha hecho para mí mucho más: ha sido y es mi segunda patria, la que me ha dado una segunda conciencia cultural e histórica - la conciencia hispánica, no en el lugar de la conciencia universal sino como forma específica de ésta, y me ha permitido integrarme en el gran mundo cultural hispánico. En Uruguay he desarrollado mi teoría lingüística en todo lo esencial, de suerte que mucho de lo que he publicado después (y de lo que sigo publicando) procede de manuscritos, esbozos y notas de mi época uruguaya.

Uruguayo se hizo Coseriu de corazón y siendo uruguayo de pasaporte murió. Y aun puede decirse que el perfecto español que hablaba tenía un suave y dulce acento uruguayo. Tras breves estancias como Profesor en las Universidades alemanas de Bonn y de Fráncfort (1963-65), aceptó la llamada que le hizo la Universidad de Tubinga y allí se asentó definitivamente, desde 1966 hasta su muerte, desempeñando las Cátedras de Filología Románica y de Lingüística General, en los últimos años con la categoría de profesor emérito. $\mathrm{Su}$ agradecimiento a Alemania lo expresó Coseriu en los siguientes términos:

[La universidad alemana] me ha ofrecido posibilidades inmejorables de pesquisa y de formación de investigadores (alemanes y no alemanes). Así la pequeña «Escuela de Montevideo" pudo convertirse en la «Escuela de Tubinga», representada hoy por una larga

Odisea, $\mathrm{n}^{\circ} 3,2003$ 
serie de docentes universitarios, tanto en Alemania como en otros países, desde Sudamérica hasta Japón.

En efecto, el largo y fructífero periodo alemán ha servido para dar universalidad a las ideas coserianas y Tubinga ha sido el centro desde el que su prestigio científico alcanzó la cima. Desde Tubinga fue que su proyección internacional lo llevó a ser solicitado constantemente para impartir cursos, pronunciar conferencias, participar en congresos por el mundo entero, de tal forma que cualquier evento relacionado con la filología y con la lingüística alcanzaba el máximo relieve internacional con la sola presencia de Coseriu. En Tubinga se constituyó, en efecto, una «Escuela Coseriana» cuyos miembros ocupan cátedras de Filología Románica y de Lingüística en numerosas universidades de todo el mundo. Y en Tubinga quedó, y esperemos que para siempre, su formidable biblioteca, posiblemente la más importante que nunca se haya formado sobre temas lingüísticos, y su valiosísimo archivo personal, entre cuyos papeles queda inédita casi tanta obra, y tan importante, como la ya publicada, al decir de quienes mejor lo conocen, los profesores José Polo y Benjamín García Hernández, de la Universidad Autónoma de Madrid, quienes desde hace varios años vienen trabajando en él, ordenándolo, catalogándolo y preparando sus originales para la imprenta.

Y en Tubinga murió Eugenio Coseriu el día 7 de septiembre de 2002, a los 81 años, en plena madurez intelectual, con las fuerzas casi enteras y con tantos proyectos por realizar como suelen tener los grandes hombres de ciencia cuando una vida terrenal, tan breve para ellos, se les acaba.

\section{SU VINCULACIÓN CON ESPAÑA}

La obra de Eugenio Coseriu se conoce hoy en el mundo entero, pero muy especialmente en España, añadiríamos nosotros. La especial devoción que Eugenio Coseriu sentía por España la confesó él mismo:

España ha sido el país que me ha proporcionado la lengua de la ciencia — la lengua que utilizo de preferencia en mis escritos y a la que se traduce todo lo que he escrito o escribo en otras lenguas - y que, más que ninguna otra, ha contribuido a la difusión de los resultados de mis reflexiones e investigaciones, tanto por los muchos libros que aquí he editado como por los innumerables cursos, congresos y coloquios científicos organizados por instituciones españolas en que he participado. Las versiones de mis trabajos que hoy «hacen fe» son las españolas; y del español he sido traducido al japonés, al coreano, al finlandés, al griego, al portugués, al francés, e incluso a mis primeras lenguas: al rumano y al italiano.

En efecto, la editorial Gredos de Madrid ha publicado lo principal de su obra édita, y cabe decir aquí que ha sido un canario, el Profesor Marcos Martínez, el traductor principal de Coseriu desde el alemán. Y la editorial Gredos fue quien publicó un libro en 5 vols. de Homenaje al Profesor Coseriu (1981) cuando éste cumplió 60 años. Además de ello, Eugenio Coseriu ha tenido una relación constante y muy afectiva con España, primero a través de los Cursos de Verano de Málaga, dirigidos por otro de los grandes filólogos y lingüistas del 
siglo XX, Manuel Alvar, Doctor honoris causa también de nuestra Universidad, y después por medio de cursos, seminarios y conferencias en múltiples universidades españolas, además de participar en innumerables congresos nacionales e internacionales organizados en España. Por ello, aparte los Doctorados honoris causa de las Universidades españolas antes dichos, se le concedió la Gran Cruz de Isabel la Católica (en 2001) y era Miembro correspondiente de la Real Academia Española.

El conocimiento que Coseriu tenía del español era, sencillamente, perfecto, y el que tenía de la cultura española, asombroso. De ahí que, como se ha dicho, la prosa científica de tema lingüístico escrita en español alcanzara la máxima altura en la pluma de Coseriu. Por lo demás, el interés y la dedicación de Coseriu al español han hecho que Tubinga se haya convertido en un centro importante de difusión de la lengua española en Alemania.

Muchos somos los profesores españoles, filólogos y lingüistas, que nos profesamos «coserianos». Pero ha de reconocerse que fue Gregorio Salvador, a través de su Cátedra recién estrenada en la Universidad de La Laguna, en 1966, y posteriormente desde sus Cátedras de Granada y de Madrid, el primero que introdujo el nombre y el pensamiento de Coseriu en España.

Puede decirse que La Laguna fue la primera universidad española receptiva a los nuevos planteamientos estructurales de la semántica que desde 1964 empezaron a desarrollar Eugenio Coseriu y Bernard Pottier. La primera y la que con más intensidad se dedicó a los estudios semánticos. Hoy es justamente famosa la llamada «Escuela semántica de La Laguna», que si tuvo en Gregorio Salvador a su fundador, tuvo después a otra figura sobresaliente, a Ramón Trujillo, también Doctor honoris causa de nuestra Universidad, y a un buen número - entonces - de jóvenes licenciados, entre los que me contaba, que se doctoraron con sendas tesis doctorales sobre semántica léxica. No sin razón, al propio Eugenio Coseriu le oí decir en público que, gracias a los estudios salidos de la Universidad de La Laguna, el español era la lengua en que mayores y mejores estudios se habían hecho de su léxico, desde una perspectiva estructural.

La deuda intelectual que todos los universitarios españoles de cualquier clase de Filología, aunque muy especialmente los de las Filologías clásica, románica y española, tenemos con el Profesor Coseriu es tan grande, que no es ninguna hipérbole decir que no hubiera sido la misma nuestra formación lingüística con o sin su obra. Hasta ese punto ha sido fundamental, absolutamente crucial la obra de Eugenio Coseriu.

\section{SU VINCULACIÓN CON LA UNIVERSIDAD DE LAS PALMAS}

La vinculación que el Profesor Coseriu tuvo con la Universidad de Las Palmas de Gran Canaria fue breve y se produjo en los últimos años, pero fue intensa y muy grata para él, según nos confesó en reiteradas ocasiones. Se inició en 1998 con un curso sobre «La semántica en la lingüística del siglo XX», organizado por la Facultad de Filología, con la asistencia al mismo de más de 250 alumnos. Continuó después siendo el Presidente del Tribunal que juzgó la tesis doctoral del Profesor Eladio Santana Martel, y como conferenciante en la Facultad de Traducción e Interpretación. De alguna de esas sus visitas a Las Palmas se hicieron eco La Provincia (10 de noviembre de 1998) y la Revista Calibán de los alumnos de la Facultad de Filología.

Odisea, $n^{\circ} 3,2003$ 
Por lo que a mí respecta, tengo a Eugenio Coseriu como a uno de los tres grandes maestros de mi formación y quehacer filológicos; los otros dos: Ramón Menéndez Pidal y Manuel Alvar. Recuerdo bien que cuando Gregorio Salvador, siendo yo estudiante en La Laguna, nos habló por vez primera de Coseriu y puso en nuestro conocimiento sus dos primeros trabajos de semántica estructural (Para una semántica diacrónica estructural e Introducción al estudio estructural del léxico), me empapé de aquellos planteamientos y fueron como una nueva luz que me iluminaron en la comprensión no ya sólo de la semántica, sino de toda la lingüística. Y eso ha sido Coseriu para mí, como para tantos otros lingüistas y filólogos canarios, españoles, europeos y del mundo: el maestro, la luz que ilumina espacios oscuros y borrosos, la guía que dice el camino por donde debe caminarse.

Maestro en la distancia fue Coseriu para mí, pues nunca fui alumno suyo, pero sí discípulo permanente y agradecido, que recibió su doctrina y se benefició de su ciencia. Y si no bastara ello para el reconocimiento que a él le debo, que sí basta, otro motivo personal tengo yo de agradecimiento al Profesor Coseriu: el magistral prólogo que puso a mi Diccionario de toponimia canaria (1999), texto que va más allá de la función meramente protocolaria y ponderativa que suelen tener los prólogos, pues de un verdadero «estudio» se trata, el primer acercamiento que Coseriu tuvo a la toponomástica, y que se ha convertido, como todo lo que salía de su pluma, en un texto ya imprescindible para la teoría de la toponimia.

El Profesor Benjamín García Hernández, en su «laudatio» sobre Eugenio Coseriu, con motivo de su nombramiento como Doctor honoris causa de la Universidad Autónoma de Madrid, me declaró a mí su discípulo, como autor que ha desarrollado una teoría lingüística de la toponimia desde presupuestos coserianos, pero, aún sin esa teoría toponomástica, también yo lo proclamo con gran orgullo cada vez que tengo ocasión de ello. Ser discípulo de Coseriu, ser seguidor de las ideas lingüísticas de Coseriu, representa - me parece a míuna manera cabal e integradora de entender los problemas lingüísticos, de ser lingüista hoy en día.

\section{CONSTRUCCIÓN COHERENTE DE UNA LINGÜÍSTICA INTEGRAL}

En lingüística, como en cualquier otra rama del saber, hay dos tipos de estudiosos y de estudios: los que se fijan en hechos particulares, los que analizan los datos concretos de un estado de habla, y aquellos otros que alzan la vista a los estadios más generales del sistema para descubrir las leyes que los gobiernan. Los primeros tienen el valor que en cada caso tengan, pero los segundos logran la categoría de fundamentales, pues fundamento establecen en que apoyar los estudios particulares; son iluminadores, puesto que prestan nueva luz para ver una problemática antes no percibida; y son universales, por cuanto son de aplicación a todas las lenguas y a todas las cuestiones particulares de cada lengua. De estos segundos son todos los estudios de Coseriu, puesto que afectan a la teoría misma, a las leyes más generales de la lingüística, al pensamiento primero que ofrece la luz para poder entender e interpretar los hechos particulares.

Por ello puede decirse, y con razón, que todo lo que ha escrito Eugenio Coseriu se ha convertido en bibliografía fundamental, que nada de lo salido de su pluma es secundario, él que tanto huyó de la banalidad. Y como a ningún aspecto de la lingüística ha sido ajeno el pensamiento coseriano, en todas las ramas del saber lingüístico aparecerá el nombre de 
Coseriu entre la bibliografía de obligada referencia, entre la bibliografía ineludible. Todo lo que se haga en lingüística en el siglo XXI deberá tener presente la obra de Coseriu.

Especial importancia han tenido dentro de su inmensa obra los estudios semánticos, los más necesitados de atención por haber sido siempre los más desatendidos, quizás por ser los más complejos. Nadie como Coseriu ha hecho tanto — ni mejor, por supuesto — por el estudio del significado, y no ya sólo en el siglo XX, sino en toda la historia de la lingüística; así que con toda razón se puede y se debe hablar de «la semántica de Coseriu» como de la aportación teórica y metodológica más importante de la lingüística para un estudio científico del léxico. Y todo ello, dentro del marco más estricto y ortodoxo de la lingüística creada por Saussure, es decir, de la verdadera lingüística, la que toma el método y estudia los hechos de y desde la propia lengua, a diferencia de otras varias lingüísticas y semánticas que se han sucedido a lo largo del siglo XX. De tal manera que la semántica de Coseriu aparece como la única verdadera semántica lingüística.

Una cualidad excepcional tiene su obra: la de ser estructural. Y el término estructural debe entenderse aquí no en el sentido restringido de un método y de una rama de la lingüística moderna, que, en parte, como todo el mundo sabe, también lo es, sino en un sentido más amplio, la de ser una obra totalmente estructurada. Porque ser estructuralista es más una forma de ser que de una actitud científica, más una manera de pensar que una manera de obrar; es, en definitiva, una manera de ver las cosas. Digamos que no sería posible lo segundo sin ser antes lo primero. Ser estructuralista supone concebir sistemas completos y generales y considerar cualquier hecho como perteneciente a un sistema, dentro del cual existe, funciona, se relaciona con otros hechos y tiene el sentido que tiene. La obra de Coseriu va destinada a aclarar los problemas básicos de la lingüística actual. Y ello concebido bajo una misma y coherente teoría lingüística, conforme a las leyes mismas del lenguaje, de forma que su obra entera es una monumental teoría, sometida toda ella a una prodigiosa organización estructural.

Coseriu fue estructuralista, sí, ahora en el sentido más restringido del término, y hasta se le tiene como a uno de los paladines del estructuralismo lingüístico, pero lo fue sólo en parte, porque — según sus propias palabras - también el estructuralismo tiene sus alcances y límites. Ha sido estructuralista sólo en lo concierne a la lingüística basada en oposiciones, sólo a lo que en el hablar y en el saber hablar es estructura opositiva, y eso, además, en el sentido humboldtiano de considerar el sistema lingüístico un sistema dinámico de posibilidades.

\section{HONOR PARA LA UNIVERSIDAD DE LAS PALMAS}

Llegados al final de esta «laudatio», cabe decir ahora que al nombrar a Eugenio Coseriu como Doctor honoris causa de la Universidad de Las Palmas de Gran Canaria, honramos la memoria del sabio lingüista rumano, a la que tanto debemos los que de una u otra forma nos dedicamos a la enseñanza de la lengua y a la investigación de sus problemas, pero, a la vez, se honra también nuestra Universidad, y nos honramos nosotros, sus profesores y alumnos, al quedar para siempre inscrito su nombre entre los que formaron su claustro académico. Poder contar con el nombre de Eugenio Coseriu es para la Universidad de Las Palmas de 
Gran Canaria un honor y un privilegio. Un título que dignifica una de las dimensiones más definidoras de la actividad universitaria: el reconocimiento al maestro, la celebración de la inteligencia, la proclamación de la vida ejemplar de un hombre dedicado por entero a una obra ejemplar.

Así pues, considerados y expuestos todos estos hechos, dignísimas autoridades y miembros de la Comunidad Universitaria, solicito con toda consideración y encarecidamente ruego que se otorgue y confiera al Señor Eugenio Coseriu el supremo grado de Doctor «honoris causa», in memoriam, por la Facultad de Filología, la Facultad de Traducción e Interpretación y la Facultad de Formación de Profesorado de la Universidad de Las Palmas de Gran Canaria. 